\title{
Efficacy of Chinese herbal prescriptions containing Ejiao or Velvet antler for management of uterine fibroids: a systematic review and meta-analysis of randomized controlled trials
}

\author{
Qinglin Li ${ }^{1 \#}$, Lizhuo Zhang ${ }^{2 \#}$, Xiaoling Qian ${ }^{3 \#}$, Yelin $\mathrm{Ma}^{3}$, Weijia Yang ${ }^{3}$, Minchun Yang ${ }^{3}$, Yijing $\mathrm{Ye}^{3}$ \\ ${ }^{1}$ Department of Traditional Chinese Medicine, Cancer Hospital of the University of Chinese Academy of Sciences; Zhejiang Cancer Hospital, \\ Hangzhou, China; ${ }^{2}$ Second Clinical Medical College, Zhejiang Chinese Medical University, Hangzhou, China; ${ }^{3}$ Department of Traditional Chinese \\ Medicine, Zhejiang Hospital, Hangzhou, China \\ Contributions: (I) Conception and design: Q Li, Y Ye; (II) Administrative support: X Qian; (III) Provision of study materials or patients: Y Ma, W \\ Yang; (IV) Collection and assembly of data: Y Ye, L Zhang; (V) Data analysis and interpretation: M Yang, L Zhang; (VI) Manuscript writing: All \\ authors; (VII) Final approval of manuscript: All authors. \\ "These authors contributed equally to this work. \\ Correspondence to: Yijing Ye; Minchun Yang. Zhejiang Hospital, 12 Lingyin Road, Xihu District, Hangzhou 310013, China. \\ Email: zjyy_yyj@163.com; 15336522560@163.com.
}

Background: To evaluate the efficacy and safety of the controversial Chinese herbal prescriptions containing Ejiao or Velvet antler (VA) in the treatment of uterine fibroids.

Methods: We searched 4 famous Chinese databases, the Chinese Clinical Trial Registry, PubMed, Cochrane Central, Google Scholar, Embase, and J-STAGE up to July 2019. We included all eligible randomized controlled trials (RCTs) which compared Chinese herbal prescriptions containing Ejiao or VA (E/VA) with placebo, pharmaceutical intervention, surgery, or other traditional Chinese medicines (TCMs) for uterine fibroids and assessed the risk of bias according to the Cochrane Collaboration's tool. The software Review Manager (RevMan) 5.1 was used for data analysis.

Results: A total of 9 RCTs involving 844 patients were identified. Meta-analyses demonstrated that TCM (E/VA) plus mifepristone reduced the volume of uterine fibroids to a greater degree than mifepristone alone [standardized mean difference (SMD): $0.59,95 \%$ CI: 0.33 to $0.85, \mathrm{P}<0.00001, \mathrm{I}^{2}=50 \%$ ]; TCM (E/VA) did not enlarge the volume of fibroids when menopausal hormone therapy (MHT) significantly increased the volume (SMD: $1.06,95 \% \mathrm{CI}: 0.73$ to $1.38, \mathrm{P}<0.00001, \mathrm{I}^{2}=0$. The uterine volume change difference was larger via combination therapy of TCM (E/VA) and mifepristone than that of mifepristone (SMD: 0.29, 95\% CI: 0.09 to $0.49, \mathrm{P}=0.005, \mathrm{I}^{2}=0 \%$ ). The TCM (E/VA) group of had an advantage over the control group in the improvement of fibroid-related symptoms [relative risk (RR): 1.24, 95\% CI: 1.15 to $1.35, \mathrm{P}<0.00001$, $\left.\mathrm{I}^{2}=0 \%\right]$. It was found that TCM (E/VA) plus mifepristone could lower estradiol (E2) levels to a greater degree than mifepristone alone (SMD: $1.63,95 \%$ CI: 0.42 to $2.83, \mathrm{P}=0.008, \mathrm{I}^{2}=97 \%$ ), as well as progesterone (P) level (SMD: $0.79,95 \%$ CI: 0.55 to $1.04, \mathrm{P}<0.00001, \mathrm{I}^{2}=43 \%$ ) in non-menopausal women. A total of 5 studies reported adverse events (AEs), the TCM (E/VA) group was potentially safer than the control group, with lower incidence of AEs (RR: 0.24, 95\% CI: 0.15 to $0.40, \mathrm{P}<0.00001, \mathrm{I}^{2}=25.8 \%$ ).

Discussion: TCM prescriptions containing E/VA seemed superior to the control group in shrinking the volume of uterine fibroids and uterus, improving related symptoms, and reducing non-menopausal women's E2 and P levels, with lower incidence of AEs.

Keywords: Chinese herbal prescription; Ejiao; Velvet antler (VA); uterine fibroids; meta-analysis

Submitted May 18, 2021. Accepted for publication Aug 17, 2021.

doi: 10.21037/apm-21-1755

View this article at: https://dx.doi.org/10.21037/apm-21-1755 


\section{Introduction}

Uterine fibroid is the most common benign tumor in gynecology, with high occurrence in women during their 30 to $50 \mathrm{~s} \mathrm{(1).} \mathrm{Uterine} \mathrm{fibroid} \mathrm{has} \mathrm{a} \mathrm{morbidity} \mathrm{of}$ about $20-25 \%$, and it is also one of the main reasons for hysterectomy (2-4). The clinical manifestations can be asymptomatic, but some women suffer from menstrual irregularities, lower abdominal masses, pelvic compression and pain symptoms, infertility, severe bleeding, and anemia (5). Uterine fibroids are hormone-sensitive tumors, which are the result of co-stimulation of estrogen and progesterone $(\mathrm{P})(6,7)$. Current treatments include surgery (hysterectomy, myomectomy), uterine artery embolization (UAE), and drug therapy like gonadotropinreleasing hormone agonist $(\mathrm{GnRH})$, progesterone receptor antagonist, mifepristone, tamoxifen, androgen, and so on (8). However, the cumulative recurrence after surgery increases to $52.9 \%$ at 5 years and reaches $84.4 \%$ at 8 years (9). As for drug treatment, GnRH can cause menopausal symptoms and osteoporosis (10), while mifepristone can lead to vaginal bleeding or atypical endometrial hyperplasia $(11,12)$. Therefore, it is important to search for safer and more effective therapies in order to offer improved options to patients. In a recent systematic review and meta-analysis, Chinese herbal formula combined with western medicine were proved to provided benefit of efficacy and safety in the treatment of uterine fibroids (13).

Ejiao (E) and Velvet antler (VA) are widely used in gynecology of traditional Chinese medicine (TCM). Ejiao, which is also known as donkey hide glue, nourishes yin and enriches blood according to the theory of TCM. The VA is a kind of accessory organ of deer which can continuously shed and regenerate every year. It tonifies the liver, kidney, and nourishes essence. Modern pharmacological studies have found that Ejiao and VA could have many biological effects such as immunomodulatory, anti-inflammatory, anti-cancer, analgesic, anti-fatigue, anti-osteoporosis, antioxidant, hypoglycemic, and hematopoietic actions (14-20). There are many famous traditional gynecological prescriptions containing Ejiao and VA, such as Huanglian Ejiao decoction, Jiaoai decoction, Wenjing decoction, Yanghe decoction, Yougui decoction, and so on. As uterine fibroids are often accompanied by abnormal vaginal bleeding, anemia, or kidney-essence deficiency, many physicians apply these 2 herbal drugs in uterine fibroid management, to reduce their volume and improve these symptoms (21-23). However, some pharmacological studies have found that Ejiao can promote the growth of human endometrium, accelerate the blood supply of uterine arteries, and increase the estradiol $\left(\mathrm{E}_{2}\right)$ value in the blood before ovulation (24). It has also been found that VA, which contains estradiol, can increase the weight of uterus and ovaries in female rats or mice $(25,26)$. The case-control study of Zhu suggested that inappropriate consumption of health care products such as Ejiao and VA may be positively related to endometrial hyperplasia and uterine fibroids (27). Therefore, many Chinese medicine doctors have held the belief that the use of Ejiao and VA should be avoided in the case of uterine fibroids (27). Aiming to explore whether these 2 common Chinese herbal medicines are safe and effective in the treatment of uterine fibroids, we conducted a meta-analysis of 9 RCTs in accordance with the inclusion criteria, with a view to provide valuable clinical evidence for resolving this controversy. We present the following article in accordance with the PRISMA reporting checklist (available at https://dx.doi.org/10.21037/apm-21-1755).

\section{Methods}

\section{Inclusion/exclusion criteria}

\section{Study types}

We selected RCTs assessing the efficacy and safety of Chinese herbal medicine containing Ejiao or VA (E/VA) in the treatment of hysteromyoma. The study language was restricted to Chinese, English, and Japanese.

\section{Types of patients}

We included patients with uterine fibroids diagnosed by ultrasonography, clinical symptoms, and signs; however, ultrasonography confirmation was the key diagnostic criteria.

\section{Exclusion criteria}

The exclusion criteria for studies were as follows: abstract with incomplete data, review, experience summary, theory study, animal experiment, case report, duplicate study, research with suspicious authenticity such as data fraud and plagiarism or missing data which could not be supplemented by contacting the author.

\section{Types of interventions}

Chinese herbal prescriptions containing any amount of Ejiao, VA, antler glue, pilose antler, and gelatinum cornus cervis were included. The prescription preparations were 
not restricted to decoction, oral liquid, capsule, or pill. TCM could be used alone or in combination with other treatment such as surgery, acupuncture, and western medicine. The dose and frequency of drugs and the course of treatment were not limited. In this study, the shortest treatment duration was 3 months, while the longest was 9 months.

\section{Outcome assessment}

The primary outcome measure was the volume change difference of fibroids and uterus measured by ultrasonography before and after treatment, serum hormone value change difference before and after treatment $\left(\mathrm{E}_{2}, \mathrm{P}\right)$, uterine fibroids symptoms improvement. Secondary outcomes were assessed via adverse reactions of drugs and follow-up.

\section{Search strategy}

We searched 4 well-known Chinese databases, including the China National Knowledge Infrastructure (CNKI), Chinese Scientific Journals Database (VIP), China Biomedical Literature Service System (SinoMed), and Wanfang Database, and in addition to the Chinese clinical trial registry, PubMed, Cochrane Central, Excerpta Medica database (EMBASE), J-STAGE (Japan Science and Technology Information Aggregator, Electronic), and Google Scholar were also searched. The retrieval time spanned from the beginning of each database to July 2019. Search terms were myoma of uterus, uterine benign tumor, leiomyoma of the uterus, uterine myoma, uterine leiomyoma, hysteromyoma, fibroid, myoma of uterus, uterine fibroid, Chinese medicine, Chinese herbal medicine, donkey-hide gelatin, colla corii asini, ass-hide gelatin, E-gelatin, E Jiao, Ejiao, antler glue, colla cornus cervi, deerhorn glue, antler gelatin, VA, Lurong, antlers, antlers cream, pilose antler, and gelatinum cornus cervis, random, control, and trial.

\section{Literature selection and data extraction}

Literature selection and data extraction were conducted independently by 2 authors, followed by screening of the title and abstract, and reading of the full text where necessary. The extracted information included: population, age, baseline conditions, interventions of the experimental and control group, follow-up, and measurement of outcomes. If any disagreement arose between the 2 investigators, a third author was consulted and resolution was reached through discussion.

\section{Methodological quality evaluation}

The methodological quality of included studies was evaluated using the bias risk assessment tool recommended by the Cochrane collaboration (28), including 6 aspects: random sequence generation; allocation concealment; blinding; incomplete outcome data; selective outcome reporting; and other bias which referred to sample size estimate, baseline comparability, inclusion and exclusion criteria, and so on. Assessment of bias risk was performed independently by 2 authors, and a third author was consulted in order to resolve any disagreements by discussion.

\section{Data analysis}

We applied the software Review Manager 5.1 (RevMan, Copenhagen: The Nordic Cochrane Center, The Cochrane Collaboration, 2011) for data analysis, using risk ratios (RR) with $95 \%$ confidence intervals $(\mathrm{CI})$ for binary data and mean difference (MD) with $95 \%$ CI for continuous outcomes, respectively. Standardized mean difference (SMD) analyses were performed when different measurement scales were used or there was a big difference in mean among trials. The fixed-effects model was used unless there was evidence of heterogeneity. We applied the chi-squared test and the $\mathrm{I}^{2}$ statistic for heterogeneity assessment and set the standard of substantial heterogeneity when $\mathrm{I}^{2}$ statistic was greater than $50 \%$. Funnel plots were generated for detection of publication bias when more than 10 trials were selected. Subgroup analysis was also performed to resolve clinical heterogeneity.

\section{Results}

\section{General description of studies}

The database search time was from inception up to 2019. We found 453 articles in total, and finally included 9 RCTs; the features of the total of 844 patients are listed in Table 1, and the flow diagram for document search is presented Figure 1. All clinical trials were conducted and published in China. The total sample size ranged from 50 to 160 participants, with approximately 94 participants per 
Table 1 Characteristics of included studies

\begin{tabular}{|c|c|c|c|c|c|c|c|c|}
\hline Study ID & $\begin{array}{l}\text { Sample } \\
\text { size }\end{array}$ & $\begin{array}{l}\text { Age (year) } \\
\text { (T/C) }\end{array}$ & $\begin{array}{c}\text { Average volume } \\
\text { of fibroids }\left(\mathrm{cm}^{3}\right) \\
(\mathrm{T} / \mathrm{C})\end{array}$ & $\begin{array}{c}\text { Average } \\
\text { course of } \\
\text { disease (year) } \\
\text { (T/C) }\end{array}$ & Intervention & Control & $\begin{array}{l}\text { Duration } \\
\text { (mm) }\end{array}$ & $\begin{array}{l}\text { Outcome mea- } \\
\text { sures }\end{array}$ \\
\hline $\begin{array}{l}\text { Yang S } \\
(29)\end{array}$ & 86 & $\begin{array}{l}38 \pm 6.3 / \\
36 \pm 5.62\end{array}$ & $\begin{array}{c}60.12 \pm 22.09 / \\
58.12 \pm 21.35\end{array}$ & NA & $\begin{array}{l}\text { Gynecological yang rong } \\
\text { capsules + mifepristone } \\
\text { (4\# tid + } 30 \text { mg once daily) }\end{array}$ & $\begin{array}{c}\text { Mifepristone } \\
\text { (30 mg once daily) }\end{array}$ & 4 & $\begin{array}{c}\text { Volume of } \\
\text { fibroids, volume } \\
\text { of uterus, } \\
\text { symptoms, } E_{2}, P\end{array}$ \\
\hline $\begin{array}{l}\text { Chen X } \\
(30)\end{array}$ & 112 & $\begin{array}{l}35.6 \pm 5.4 / \\
34.5 \pm 5.3\end{array}$ & $\begin{array}{l}61.2 \pm 14.3 / \\
60.3 \pm 14.5\end{array}$ & $\begin{array}{l}2.6 \pm 3.1 / \\
2.7 \pm 3.2\end{array}$ & $\begin{array}{c}\text { Fuke Zaizao capsules + } \\
\text { mifepristone ( } 6 \# \text { twice } \\
\text { daily }+10 \text { mg once daily) }\end{array}$ & $\begin{array}{c}\text { Mifepristone } \\
\text { (10 mg once daily) }\end{array}$ & $\begin{array}{c}6 \text { menstrual } \\
\text { cycle }\end{array}$ & $\begin{array}{c}\text { Volume of } \\
\text { fibroids, } \\
\text { symptoms, } \mathrm{E}_{2}, \mathrm{P}\end{array}$ \\
\hline $\begin{array}{l}\text { Zhang J } \\
\text { (31) }\end{array}$ & 136 & $46 \pm 5 / 45 \pm 4$ & $60 \pm 17 / 58 \pm 17$ & NA & $\begin{array}{l}\text { Fuke Zaizao capsules }+ \\
\text { mifepristone ( } 6 \# \text { twice } \\
\text { daily }+25 \text { mg once daily) }\end{array}$ & $\begin{array}{c}\text { Mifepristone } \\
\text { (25 mg once daily) }\end{array}$ & 3 & $\begin{array}{c}\text { Volume of } \\
\text { fibroids, volume } \\
\text { of uterus, } E_{2}, P \text {, } \\
A E\end{array}$ \\
\hline $\begin{array}{l}\text { Wang S } \\
\text { (33) }\end{array}$ & 100 & NA & NA & NA & $\begin{array}{l}\text { Self-made Xiaoliu } \\
\text { capsules (6\# tid) }\end{array}$ & $\begin{array}{c}\text { Guizhi Fuling } \\
\text { capsules (3\# tid) }\end{array}$ & 3 & $\begin{array}{l}\text { Volume of } \\
\text { fibroids, } \\
\text { symptoms, AE }\end{array}$ \\
\hline $\begin{array}{l}\text { Chen J } \\
\text { (34) }\end{array}$ & 60 & $47 / 47$ & $42 \pm 10 / 39 \pm 10$ & $1.16 / 1.16$ & $\begin{array}{l}\text { Kuntai capsules } \\
\text { (4\# } 3 \text { times daily) }\end{array}$ & $\begin{array}{l}\text { Climen tablets } \\
\text { (1\# once daily) }\end{array}$ & 3 & $\begin{array}{l}\text { Volume of } \\
\text { fibroids, } \mathrm{E}_{2} \text {, } \\
\text { modified } \\
\text { Kupperman } \\
\text { index (35), } \\
\text { adverse events }\end{array}$ \\
\hline $\begin{array}{l}\text { Wang F } \\
(38)\end{array}$ & 50 & NA & $\begin{array}{l}136.12 \pm 27.66 / \\
135.78 \pm 26.85\end{array}$ & NA & $\begin{array}{c}\text { Yanlurukang capsules + } \\
\text { tamoxifen } \\
\text { (4\# tid + } 10 \mathrm{mg} \text { tid })\end{array}$ & $\begin{array}{c}\text { Tamoxifen } \\
\text { (10 mg three times } \\
\text { daily) }\end{array}$ & 6 & $\begin{array}{c}\text { Volume of } \\
\text { fibroids, breast } \\
\text { pain relief, AE }\end{array}$ \\
\hline Liu X (39) & 50 & $\begin{array}{l}37.2 \pm 4.3 / \\
36.9 \pm 4.7\end{array}$ & NA & NA & $\begin{array}{c}\text { Laparoscopic } \\
\text { myomectomy + Fuke } \\
\text { Zaizao capsules } \\
\text { (10\# twice daily) }\end{array}$ & $\begin{array}{l}\text { Laparoscopic } \\
\text { myomectomy }\end{array}$ & 6 & $\begin{array}{c}\text { recurrence rate, } \\
\text { menstrual } \\
\text { improvement, } \mathrm{E}_{2}\end{array}$ \\
\hline
\end{tabular}

\footnotetext{
a, MHT, menopausal hormone therapy. The prescription was as follows: progynova $1 \mathrm{mg}$ once daily for 28 days continuously and duphaston $10 \mathrm{mg}$ per day in the last 14 days. Then, drugs were stopped and menses would generally occur in the following 1-5 days. Afterwards, the same medication cycle was repeated from the first day of menstruation; however, if menses did not occur, the next medication cycle was commenced 7 days after withdrawal. The total course of treatment was 6 months. AE, adverse events; MHT, menopausal hormone therapy; NA, not available; $E_{2}$, estradiol; P, progesterone; tid, 3 times a day.
} 


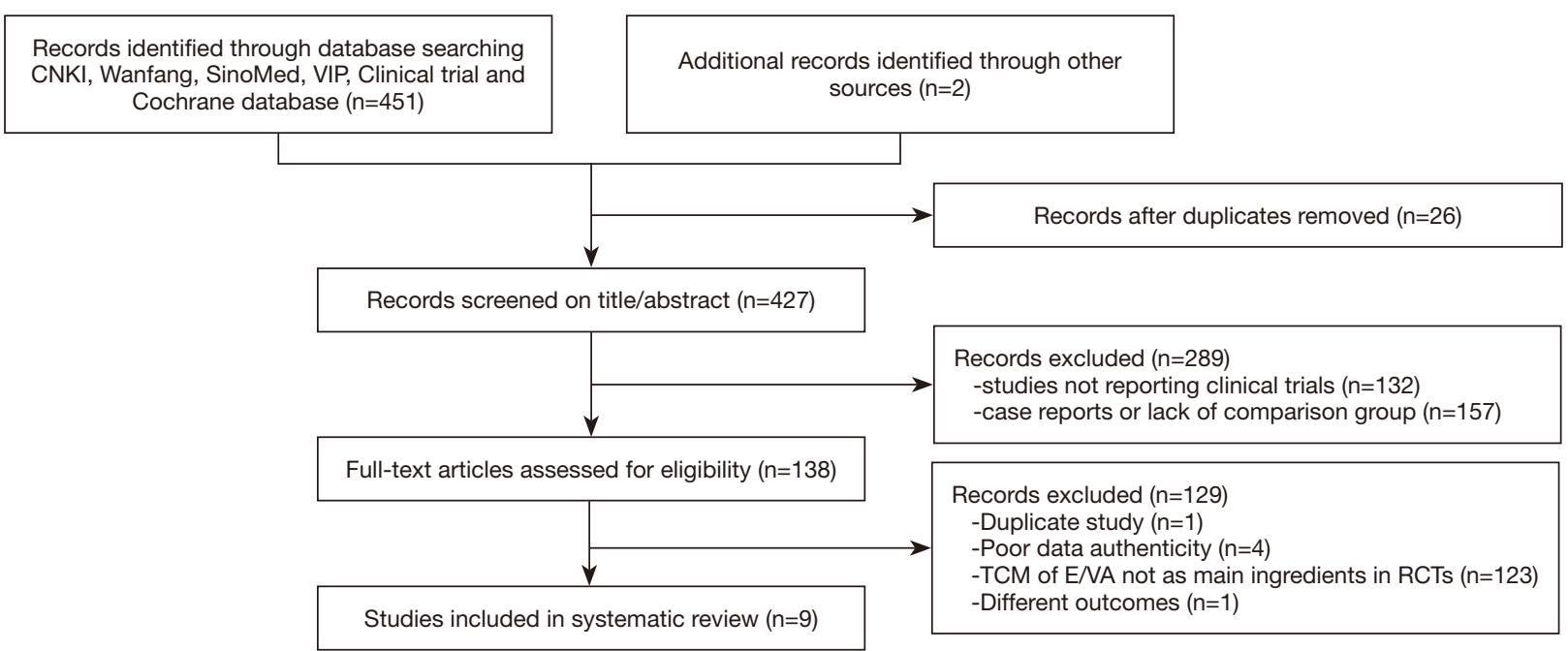

Figure 1 Flow diagram of included studies.

trial. All diagnoses were based on clinical symptoms and ultrasonography. All trials had 2 arms.

The Chinese herbal prescriptions of 9 trials containing E/VA involved Gynecological yang rong capsules, Fuke Zaizao capsules, self-made Xiaoliu capsules, Kuntai capsules, and Yanlurukang. They were approved by the State Food and Drug Administration of China. Other interventions included laparoscopic myomectomy, auricular pressing therapy, Guizhi Fuling pill, mifepristone, tamoxifen, and menopausal hormone therapy (MHT). None of the trials had adopted placebo or no intervention as control.

For outcome evaluation, there were 8 trials that measured uterine fibroid volume by ultrasonography [volume fibroid $=4 / 3 \times \pi \times a b c$, abc represented the threedimensional (3D) radii of uterine fibroid, respectively], and 7 out of 8 reported accurate quantitative values. A total of 3 trials measured the uterine volume (volume of uteri $=4 / 3 \times \pi \times$ def, def represented the $3 \mathrm{D}$ radii of the uterus, respectively). In 4 trials, the treatment validity was assessed by combined evaluation of clinical symptom improvement and reduction rate of uterine fibroids. The formula for reducing the rate of uterine fibroids was $(1-\mathrm{a} 2 \mathrm{~b} 2 \mathrm{c} 2 / \mathrm{a} 0 \mathrm{~b} 0 \mathrm{c} 0)$ $\times 100 \%$, and a $2 \mathrm{~b} 2 \mathrm{c} 2$ represented the $3 \mathrm{D}$ radii of fibroids after treatment, respectively, while a0b0c0 represented the same measurement before treatment.

\section{Methodological quality}

All included trials were parallel-group randomized trials, but only 2 trials $(22 \%, 2 / 9)$ reported the method of sequence generation, one using random number table (36) and another using visit sequence (39). No trials reported allocation concealment or blinding. No drop-out of participants was reported in all trials. A single trial described the follow-up including whether menstruation had returned to normal and whether fibroid volumes had significantly enlarged (38), no trial reported participant compliance. In view of selective reporting, as all protocols of the 9 trials were not accessible, we compared the outcome measures mentioned in the methods section with the obtained outcomes in the results and drew a conclusion that all trials reported all outcome measures described in the methods and were thus evaluated as low risk. No single trial involved pre-trial sample size estimation. Based on quality assessment, all trials were deemed to be at high or unclear risk of bias (Figures 2,3, Table 2).

\section{Effect estimation}

\section{Improvement of uterine fibroids volume TCM containing E/VA [TCM (E/VA)] plus mifepristone vs. mifepristone alone}

A total of 4 trials compared the combination of TCM (E/VA) and mifepristone with mifepristone alone in hysteromyoma treatment. The volume difference of uterine fibroids before and after treatment was calculated within the same group, and transformed to $\mathrm{SMD} \pm \mathrm{SD}$ format. It was found that compared with mifepristone, TCM (E/VA) plus mifepristone reduced the volume of uterine fibroids to a greater degree (SMD: 0.59, 95\% CI: 0.33 to 0.85 , 


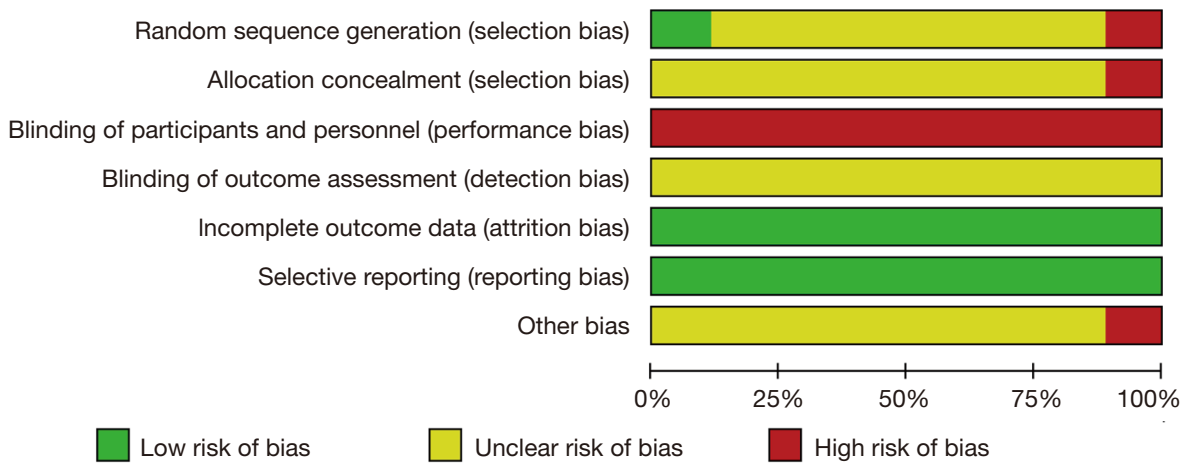

Figure 2 Graph of risk of bias.

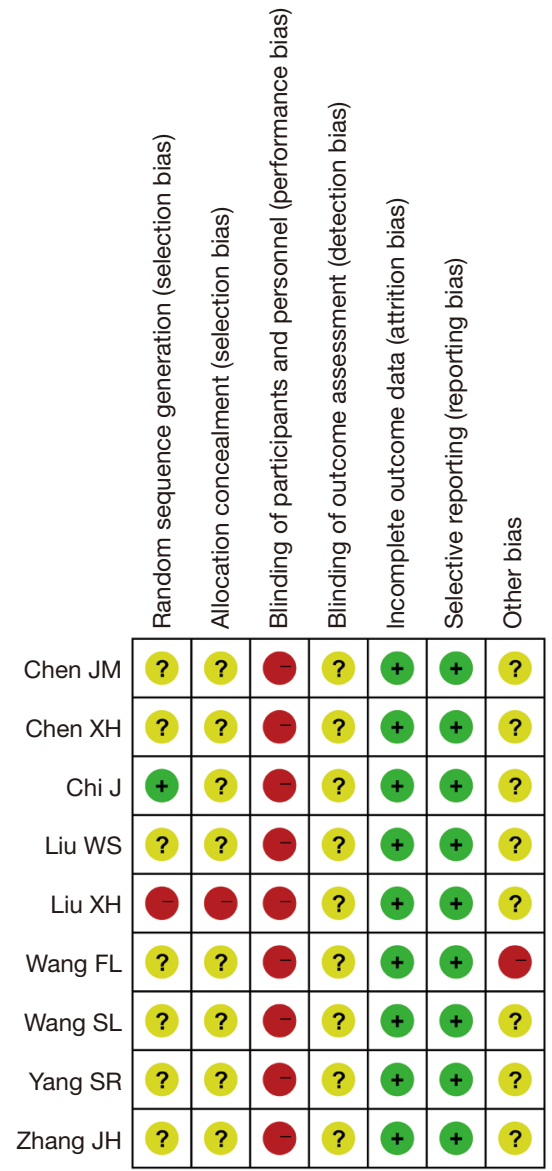

Figure 3 Summary of risk of bias.

$\mathrm{P}<0.00001, \mathrm{I}^{2}=50 \%$ ) (Figure 4).

\section{TCM (E/VA) versus MHT}

Perimenopausal uterine fibroids patients were respectively enrolled in the studies by Chi J (36) and Chen J (34), et al., in which they compared TCM (E/VA) with MHT. Also known as hormone replacement therapy, MHT was applied to help control the symptoms of menopause. As its wellknown adverse effect, MHT increased the volume of fibroids significantly, whereas TCM (E/VA) did not enlarge the volume (SMD: $1.06,95 \%$ CI: 0.73 to $1.38, \mathrm{P}<0.00001, \mathrm{I}^{2}=0 \%$ ).

\section{TCM (E/VA) plus tamoxifen vs. tamoxifen alone}

In the study of Wang F et al. (38), participants were treated with TCM (E/VA) combined with tamoxifen or the tamoxifen alone for their uterine fibroids accompanied by hyperplasia of mammary glands. No significant difference was detected between the 2 groups in volume change of fibroids (SMD: $0.21,95 \%$ CI: -0.34 to $0.77, \mathrm{P}=0.45$ ).

\section{Uterine volume improvement}

A total of 3 trials showed that the uterine volume change was larger by combination therapy of TCM (E/VA) and mifepristone than that of mifepristone alone (SMD: 0.29, 95\% CI: 0.09 to $0.49, \mathrm{P}=0.005, \mathrm{I}^{2}=0 \%$ ) (Figure 5).

\section{Improvement of fibroid-related symptoms}

A total of 4 trials assessed the effectiveness of treatment by evaluating clinical symptom improvement and shrink rate of uterine fibroids together. Fibroid-related symptoms included abnormal menstruation like hypermenorrhea, prolonged menstrual bleeding, advanced or delayed menstruation, vaginal bleeding at times other than menstruation and dysmenorrhea, possibly accompanied by constitutional symptoms as breast pain, nipple itching, distention pain of abdomen, and so on. The 2 researchers defined a volume shrink ratio of fibroids $\geq 33.3 \%$ with relief or disappearance of fibroid-related symptoms as effective (40) [RR: 1.14, 95\% CI: 0.95 to $0.1 .36, \mathrm{P}=0.15$ (28); RR: $1.34,95 \%$ CI: 1.11 to $1.63, \mathrm{P}=0.003$ (33)]. Chen XH (30) 
Table 2 Risk of bias of included studies

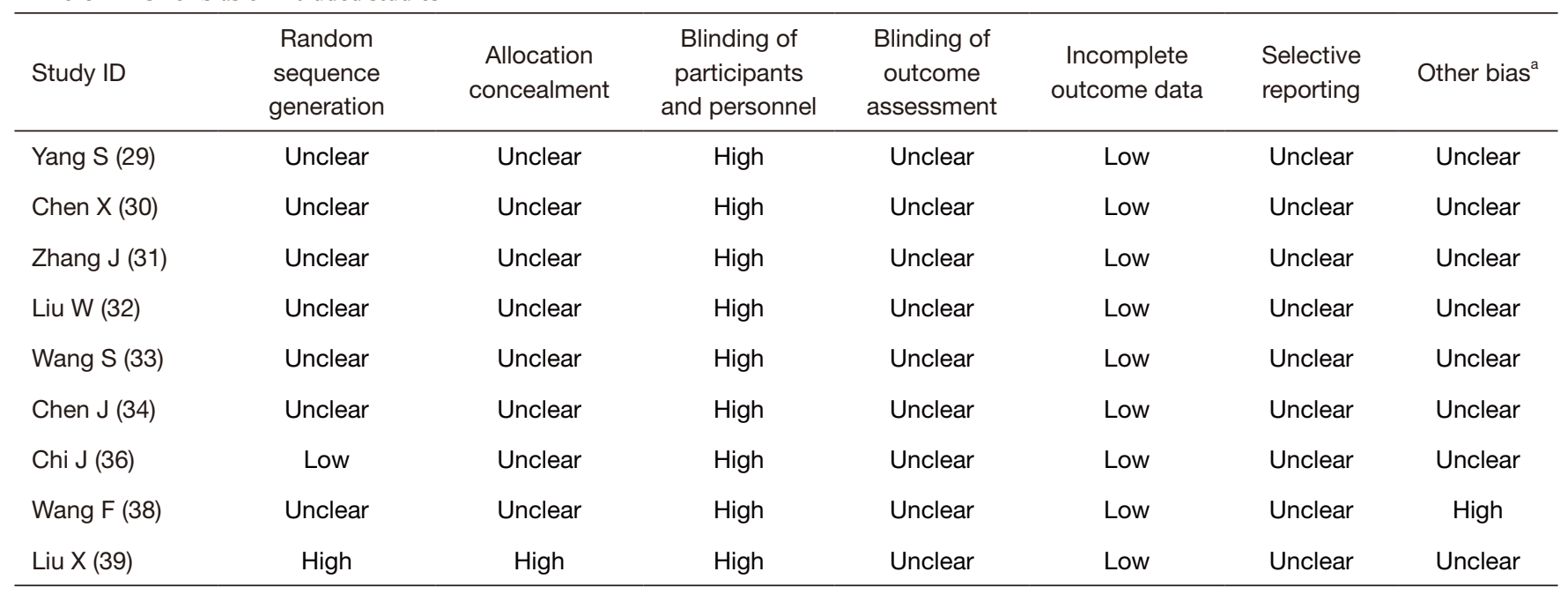

a, other bias refers to sample size estimate, baseline comparability, and inclusion and exclusion criteria.

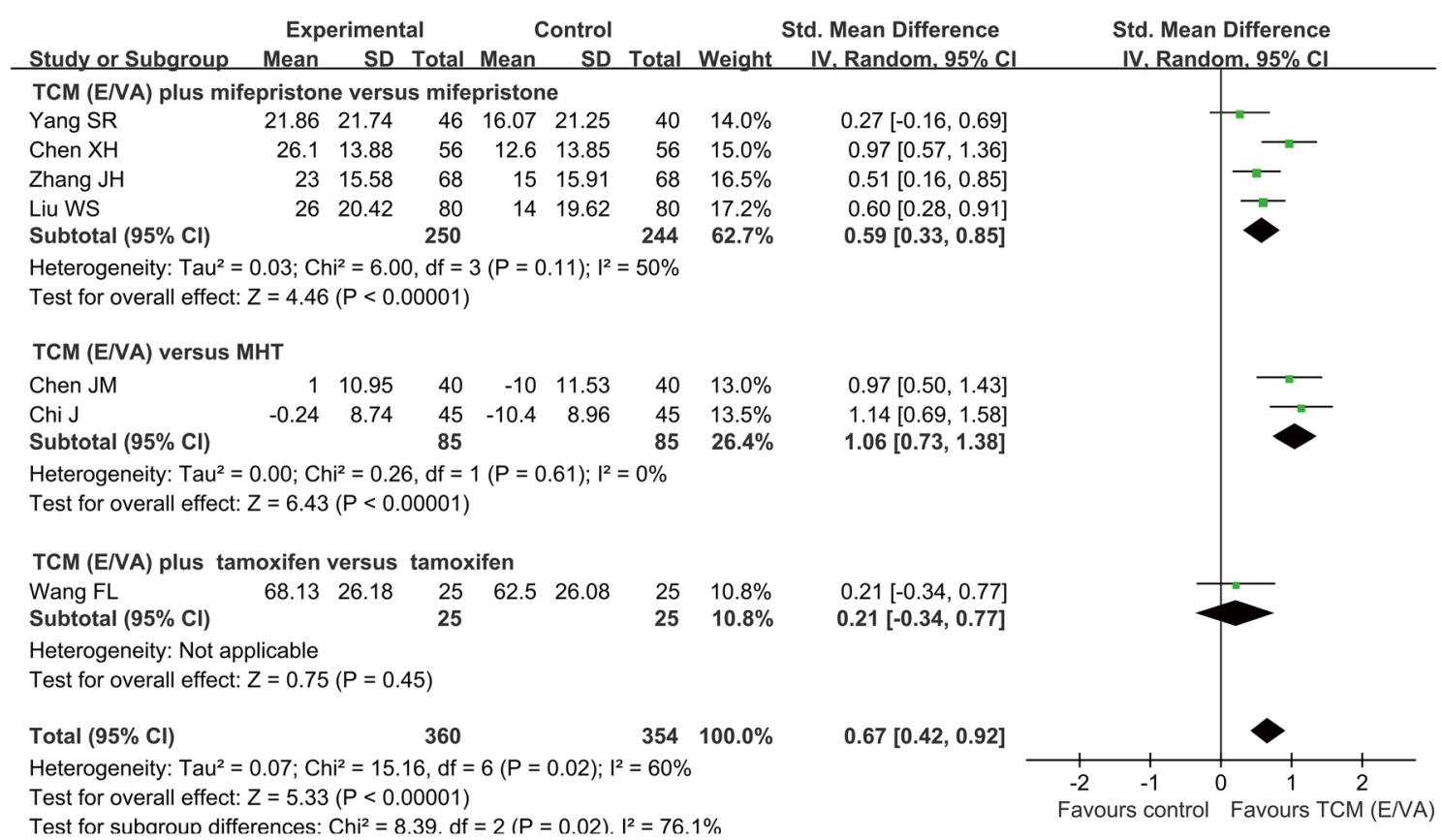

Figure 4 TCM (E/VA) group vs. control group for volume change difference of uterine fibroids. TCM (E/VA); traditional Chinese medicine (Ejiao/Velvet antler); SD, standard deviation; CI, confidence interval.

defined a volume shrink ratio of fibroids $\geq 25 \%$ with relief or disappearance of fibroid-related symptoms as effective (RR: $1.26,95 \%$ CI: 1.07 to $1.49, \mathrm{P}=0.005$ ). Liu $W$ et al. (32) defined a volume shrink as effective (did not give a specific value), and increased or unchanged volume as invalid
(RR: $1.25,95 \%$ CI: 1.09 to $1.44, \mathrm{P}=0.002)$. Overall, the experimental group of TCM (E/VA) had an advantage over the control group in improvement of fibroid-related symptoms (RR: $1.24,95 \%$ CI: 1.15 to $1.35, \mathrm{P}<0.00001$ ) (Figure 6). 


\begin{tabular}{|c|c|c|c|c|c|c|c|c|c|c|c|}
\hline \multirow[b]{2}{*}{ Study or Subgroup } & \multicolumn{3}{|c|}{ Experimental } & \multicolumn{2}{|c|}{ Control } & \multirow[b]{2}{*}{ Total } & \multirow[b]{2}{*}{ Weight } & Std. Mean Difference & \multirow{2}{*}{\multicolumn{2}{|c|}{$\begin{array}{c}\text { Std. Mean Difference } \\
\text { IV. Fixed, } 95 \% \mathrm{Cl}\end{array}$}} & \\
\hline & Mean & SD & Total & Mean & SD & & & IV. Fixed, $95 \% \mathrm{Cl}$ & & & \\
\hline Yang SR & 33.06 & 43.48 & 46 & 23.81 & 45.11 & 40 & $22.6 \%$ & $0.21[-0.22,0.63]$ & & & \\
\hline Zhang JH & 40 & 45.69 & 68 & 28 & 43.17 & 68 & $35.7 \%$ & $0.27[-0.07,0.61]$ & & & \\
\hline Liu WS & 42 & 44.05 & 80 & 29 & 26.31 & 80 & $41.7 \%$ & $0.36[0.04,0.67]$ & & & \\
\hline Total $(95 \% \mathrm{CI})$ & & & 194 & & & 188 & $100.0 \%$ & $0.29[0.09,0.49]$ & & & \\
\hline Heterogeneity: $\mathrm{Chi}^{2}=$ & $34, d f=$ & $=2(P=$ & $0.85)$ & $\left.\right|^{2}=0 \%$ & & & & & -0.5 & 0 & 1 \\
\hline
\end{tabular}

Figure 5 TCM (E/VA) group versus control group for volume change difference of uterine. TCM (E/VA); traditional Chinese medicine (Ejiao/Velvet antler); SD, standard deviation; CI, confidence interval.

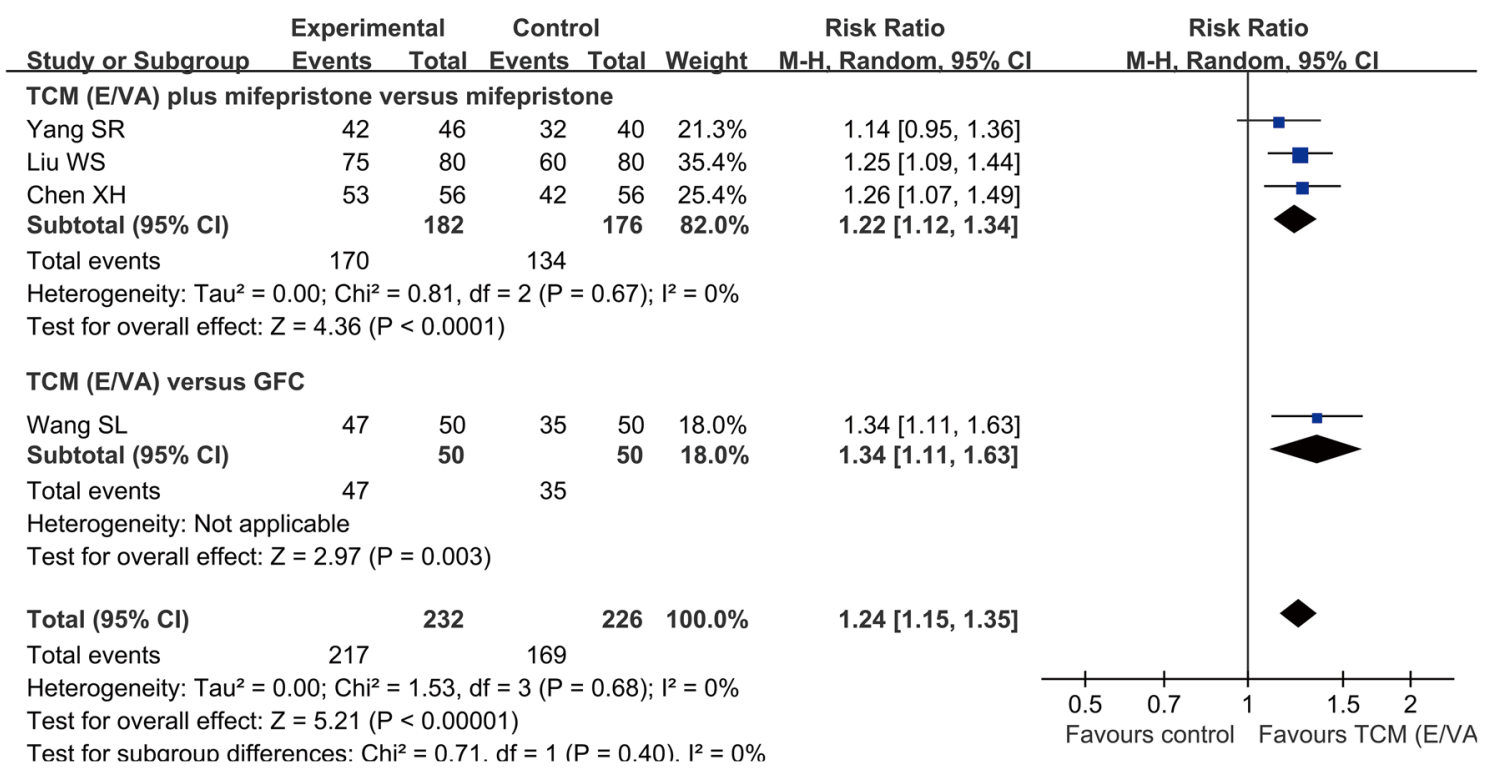

Figure 6 TCM (E/VA) group vs. control group for improvement of fibroid-related symptoms. TCM (E/VA); traditional Chinese medicine (Ejiao/Velvet antler); SD, standard deviation; CI, confidence interval.

\section{$\mathbf{E}_{2}$ change difference}

Since the units of $\mathrm{E}_{2}$ value were inconsistent (pnmol/L and $\mathrm{pg} / \mathrm{mL}$ ) as well as baseline in different trials, SMD was used as a parameter to calculate the change difference of $\mathrm{E}_{2}$ value. A total of 4 trials found TCM (E/VA) plus mifepristone could lower $\mathrm{E}_{2}$ levels to a greater degree than mifepristone alone (SMD: 1.63 , 95\% CI: 0.42 to 2.83, $\mathrm{P}=0.008, \mathrm{I}^{2}=97 \%$ ). Liu $\mathrm{X}$ et al. (39) discovered that the level of $\mathrm{E}_{2}$ was not significantly altered after treatment of either laparoscopic myomectomy combined with TCM (E/VA) or myomectomy alone. Among perimenopausal participants with uterine fibroids, $\mathrm{E}_{2}$ change difference was not significantly different between the TCM (E/VA) group and MHT group (SMD: 0.51, 95\% CI: -0.61 to $1.63, \mathrm{P}=0.37$, $\left.\mathrm{I}^{2}=90 \%\right)$ (Figure 7).

\section{$P$ change difference}

A total of 4 trials found that TCM (E/VA) plus mifepristone could reduce $\mathrm{P}$ levels by a greater degree than mifepristone alone (SMD: 0.79, 95\% CI: 0.55 to $1.04, \mathrm{P}<0.00001$, $\left.\mathrm{I}^{2}=43 \%\right)$ (Figure 8$)$.

\section{Safety assessment}

A total of $6(67 \%)$ of the 9 RCTs reported whether participants experienced $\mathrm{AE}$ during the observation period and follow-up period. Liu W et al. (32) found that a few participants suffered mild and tolerable nausea that did not require further treatment, though they did not report the exact number. Liu X et al. (39) reported that no TCMrelated AE were observed. The remaining 4 RCTs (44\%) 


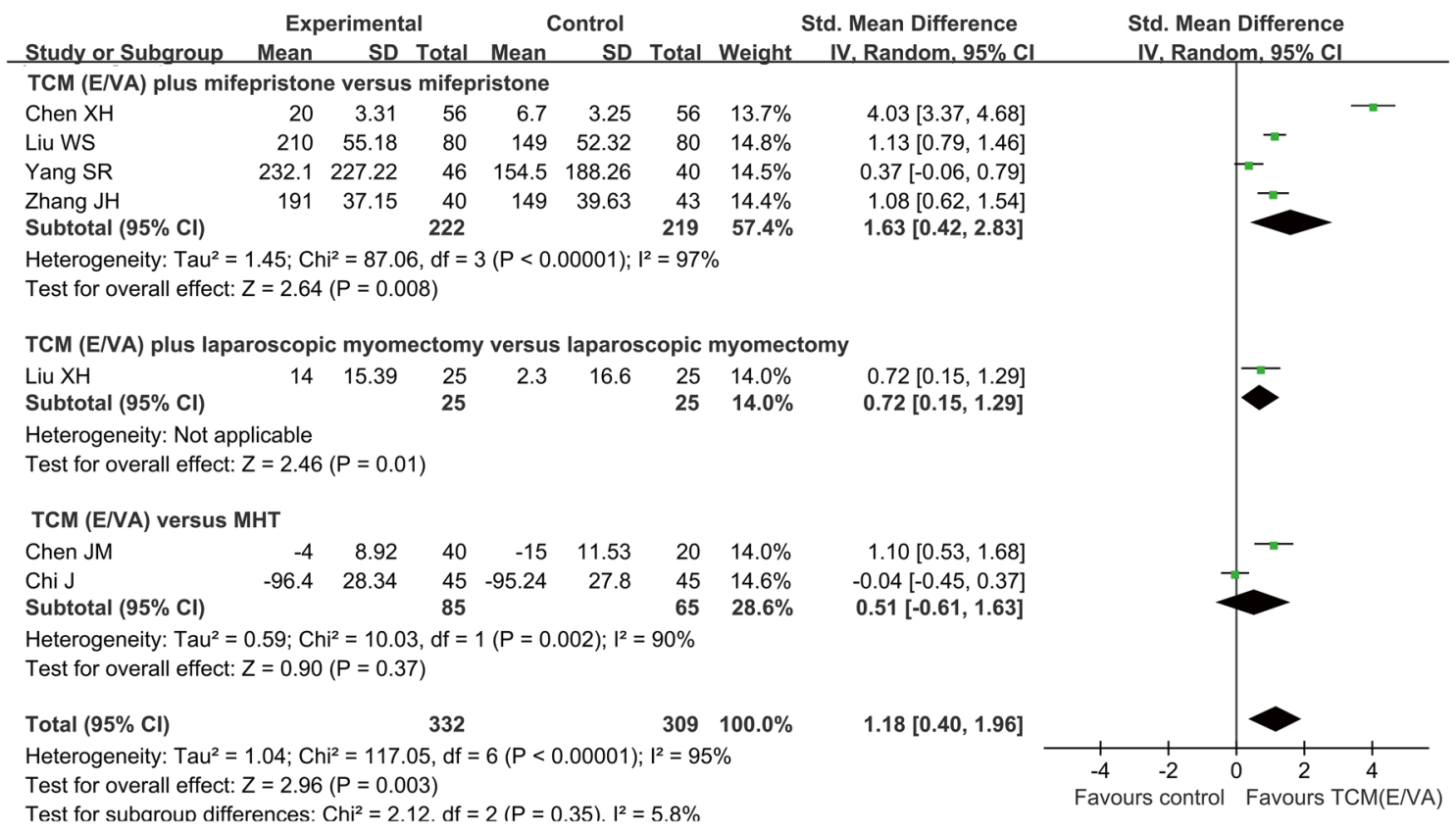

Figure 7 TCM (E/VA) group versus control group for $\mathrm{E}_{2}$ change difference. TCM (E/VA); traditional Chinese medicine (Ejiao/Velvet antler); SD, standard deviation; CI, confidence interval; $\mathrm{E}_{2}$, estradiol.

\begin{tabular}{|c|c|c|c|c|c|c|c|c|c|c|}
\hline \multirow[b]{2}{*}{ Study or Subgroup } & \multicolumn{3}{|c|}{ Experimental } & \multicolumn{3}{|c|}{ Control } & \multicolumn{2}{|r|}{ Std. Mean Difference } & \multirow{2}{*}{\multicolumn{2}{|c|}{$\begin{array}{l}\text { Std. Mean Difference } \\
\text { IV. Random. } 95 \% \mathrm{CI}\end{array}$}} \\
\hline & Mean & SD & Total & Mean & SD & Total & Weight & IV. Random, $95 \% \mathrm{Cl}$ & & \\
\hline Chen XH & 1.4 & 0.44 & 56 & 1 & 0.55 & 56 & $23.9 \%$ & $0.80[0.41,1.18]$ & & \\
\hline Liu WS & 24 & 3.92 & 80 & 20 & 3.92 & 80 & $28.4 \%$ & $1.02[0.69,1.35]$ & & \\
\hline Yang SR & 11.3 & 3.71 & 46 & 9.7 & 4.41 & 40 & $21.0 \%$ & $0.39[-0.04,0.82]$ & & \\
\hline Zhang JH & 12.7 & 2.95 & 68 & 10.1 & 3.07 & 68 & $26.6 \%$ & $0.86[0.51,1.21]$ & & \\
\hline Total $(95 \% \mathrm{Cl})$ & & & 250 & & & 244 & $100.0 \%$ & $0.79[0.55,1.04]$ & & \\
\hline $\begin{array}{l}\text { Heterogeneity: } \mathrm{Tau}^{2}= \\
\text { Test for overall effect: }\end{array}$ & $\begin{array}{l}0.03 ; \mathrm{Ch} \\
z=6.32\end{array}$ & $\begin{array}{l}i^{2}=5.2 \\
(P<0 .\end{array}$ & $\begin{array}{l}24, \mathrm{df}= \\
.00001)\end{array}$ & $3(P=$ & $.15) ;$ & $\left.\right|^{2}=439$ & & & $\begin{array}{cc} & 1 \\
-1 & -0.5 \\
\text { vours control }\end{array}$ & $\begin{array}{l}0 \quad 0.5 \\
\text { Favours }\end{array}$ \\
\hline
\end{tabular}

Figure 8 TCM (E/VA) group versus control group for P change difference. TCM (E/VA); traditional Chinese medicine (Ejiao/Velvet antler); SD, standard deviation; CI, confidence interval; $\mathrm{P}$, progesterone.

reported details of AE, as summarized in Table 3. No trial reported any serious $\mathrm{AE}$. The symptoms of breast distension pain (RR: 0.25 , 95\% CI: 0.09 to $0.71, \mathrm{P}=0.01, \mathrm{I}^{2}=0 \%$ ), amenorrhea (RR: $0.05,95 \% \mathrm{CI}: 0.00$ to $0.86, \mathrm{P}=0.04$ ), and abnormal vaginal bleeding (RR: $0.11,95 \% \mathrm{CI}: 0.03$ to 0.47 , $\mathrm{P}=0.003$ ) were found to be less frequent in the TCM (E/VA) group than the control group. In summary, meta-analysis of 5 trials found that TCM (E/VA) group was potentially safer than the control group, with lower incidence of AE (RR: 0.24, 95\% CI: 0.15 to $0.40, \mathrm{P}<0.00001, \mathrm{I}^{2}=20 \%$ ) (Figure 9).

\section{Discussion}

\section{Main findings}

In this meta-analysis, 7 trials found that the treatment containing TCM (E/VA) was more effective than the control group in reducing the volume of uterine fibroids. A single study observed that treatments containing TCM (E/VA) reduced the uterus volume to a greater degree than the control group (32). Treatment with TCM (E/VA) was found to be superior in improving hysteromyoma-related 
Table 3 RR of all reported adverse events in studies comparing TCM (E/VA) group with control group

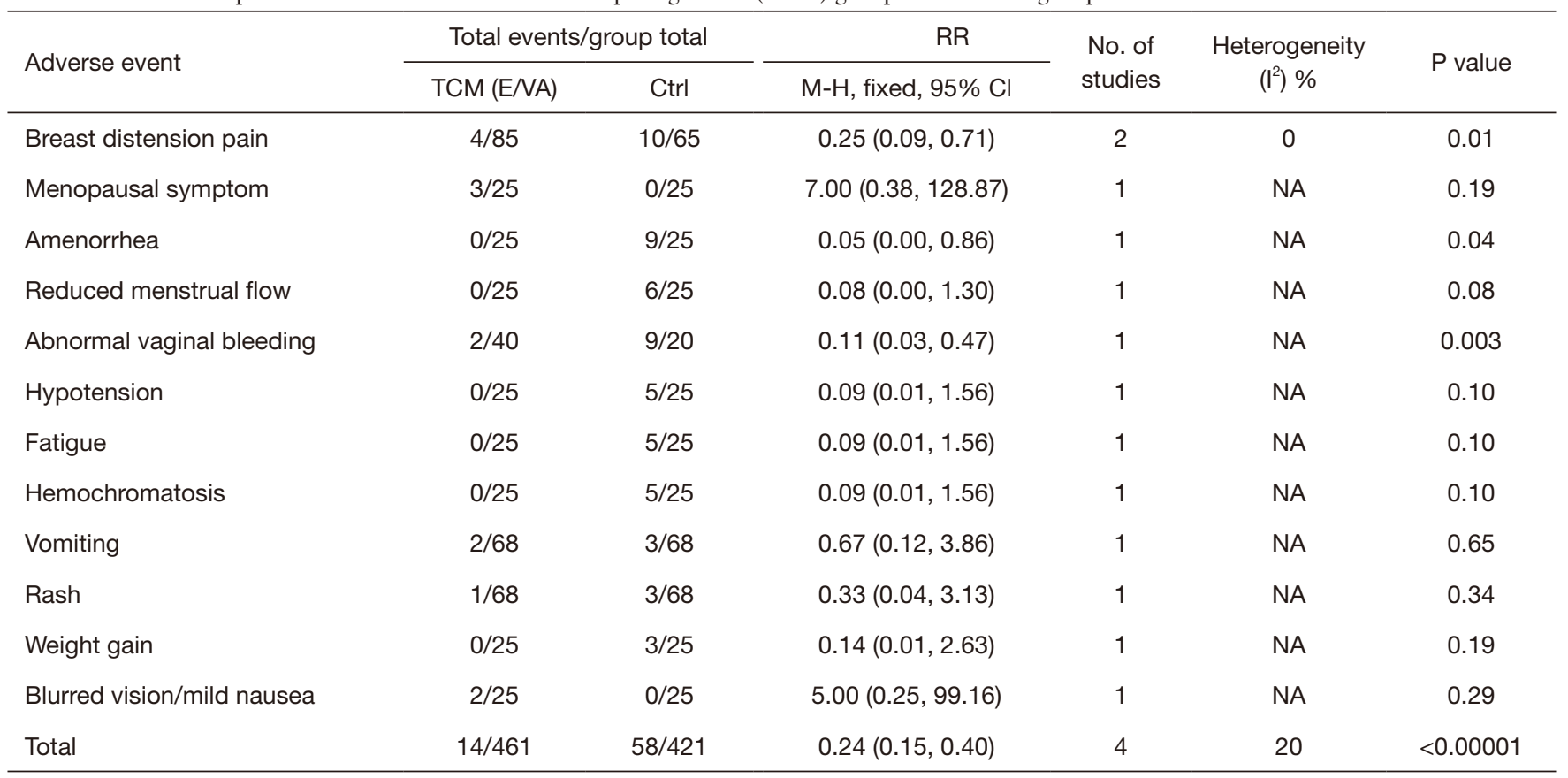

TCM (E/VA); traditional Chinese medicine (Ejiao/Velvet antler); RR, relative risk; Cl, confidence interval.

symptoms in 3 trials. A total of 4 studies found that TCM (E/VA) achieved a bigger reduction in estrogen levels of 34-46-year-old women. Although the average age of patients enrolled in Zhang J et al.'s trial (31) were 45-46 years old, which is close to menopausal age, the $\mathrm{E}_{2}$ and $\mathrm{P}$ levels of those participants were higher than normal levels and similar to 1 of the other 3 trials. Thus, these patients could not be considered as perimenopausal like those enrolled in the trials of Chi J and Chen J et al. Of these 4 studies, 3 found that TCM (E/VA) plus mifepristone was superior to mifepristone alone in reducing $\mathrm{P}$ level.

Only 2 trials estimated the improvement in quality of life associated with climacteric symptoms. Chen J (34) and Chi J et al. (36) applied the Kupperman index (35) and menopause symptom score (37) for assessment, respectively, the latter of which included physical, psychological, and social dimensions. All the above studies found that Kuntai capsules with or without auricular pressing therapy could obviously ameliorate premenopausal syndrome $(\mathrm{P}<0.5)$, but the difference was not significant when compared with the MHT group.

Of the 9 trials, 1 conducted a 6 -month follow-up after discontinuing medication (38). The follow-up rate was $88 \%(22 / 25)$ and $76 \%(19 / 25)$, respectively, for the TCM (E/VA) group and the control group and the cases with no significant increase of fibroid volume were 16 and 13 , respectively (RR: $1.23,95 \%$ CI: 0.76 to $1.98, \mathrm{P}=0.39$ ).

To sum up, these trials revealed that controversial Chinese herbal prescriptions containing E/VA could enhance the efficacy of western medicine therapy in the aspects of reducing the volume, $\mathrm{E}_{2}$ and $\mathrm{P}$ levels and improving hysteromyoma-related symptoms and life quality, and provide a safer treatment choice in addition to pure Western medicine treatment.

\section{$E_{2}$ beterogeneity analysis}

As previously mentioned, the heterogeneity of $\mathrm{E}_{2}$ change difference was notably high with $97 \%$ in the subgroup of TCM (E/VA) plus mifepristone vs. mifepristone alone. The primary cause may have been the different measurement periods of $E_{2}$ in different trials, as $E_{2}$ fluctuates considerably during the menstrual cycle. We identified that Zhang J (31) and Yang S et al. (29) detected $\mathrm{E}_{2}$ on the 35 day of the menstrual cycle, while Chen $\mathrm{X}$ and Liu $\mathrm{W}$ did not describe the detection time clearly. However, the $\mathrm{E}_{2}$ level reported in the work of Liu W (32), whether before or after treatment, was close to those of Zhang J and Yang S, while the $\mathrm{E}_{2}$ baseline of Chen $\mathrm{X}$ was very different to that of the other 3 trials, resulting in great heterogeneity in the meta- 


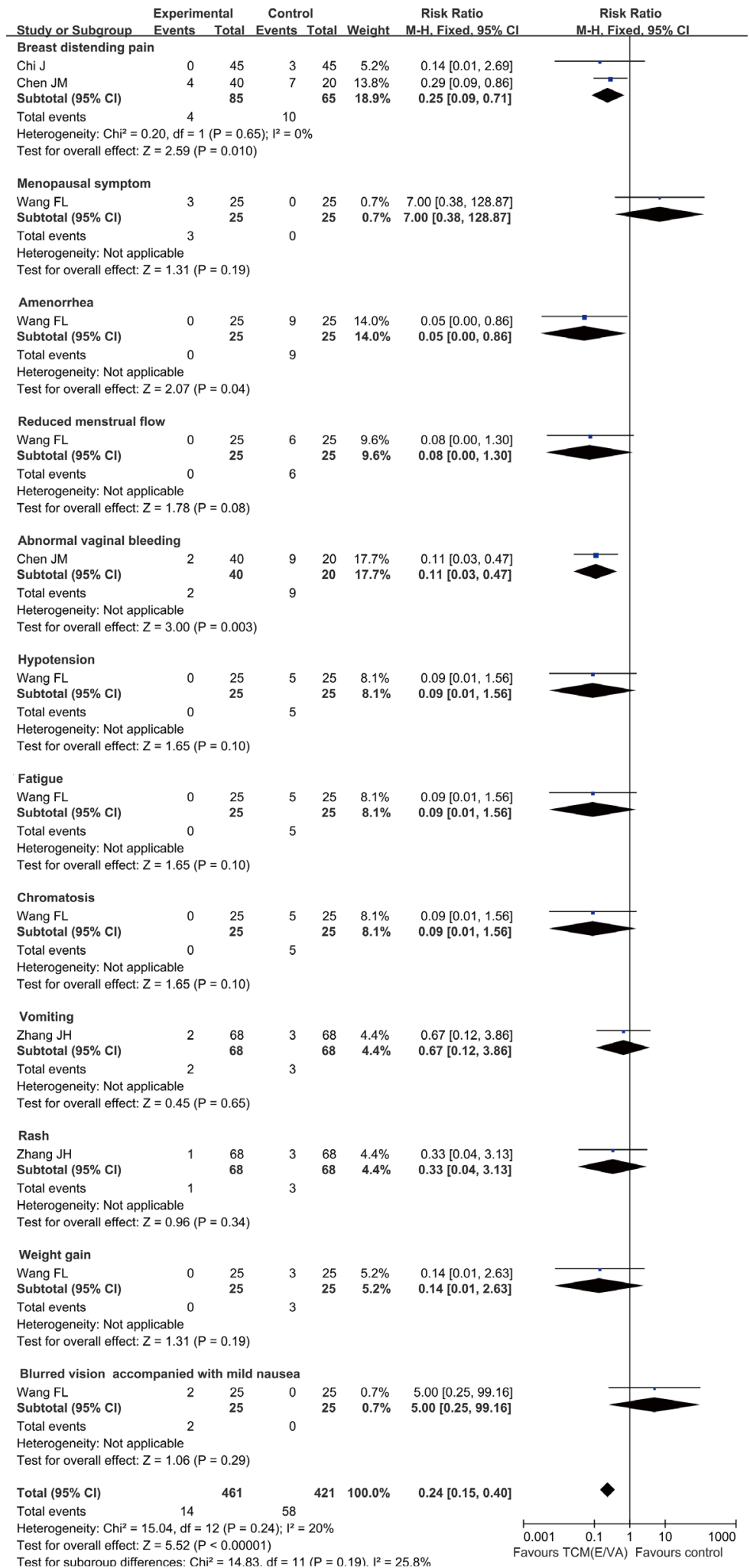

Figure 9 TCM (E/VA) group vs. control group for likelihood of AE. TCM (E/VA); traditional Chinese medicine (Ejiao/Velvet antler); SD, standard deviation; CI, confidence interval; AE, adverse events. 
analysis. In addition, all $\mathrm{SD}$ values of $\mathrm{E}_{2}$ detected by Yang SR had a wide range of fluctuation and became an additional source of heterogeneity.

\section{Major restrictions}

Our analysis had several limitations. First, the selected trials reflected poor methodological quality as assessed by the Cochrane Collaboration's risk of bias tool. A total of 7 of the 9 included trials did not mention allocation concealment, and none of the trials offered information about blinding. No trials pre-estimated the sample size, and some enrolled too few patients. Another 2 trials were excluded on account of erroneous judgment standards of fibroid shrink rate and unexplainable data. We endeavored to clarify information by sending e-mails to the authors, but received no response. Due to the sample size not exceeding 10, we did not create funnel plots.

\section{Drug mechanism}

The mechanism of TCM (E/VA) eliminating uterine fibroids and relieving symptoms might be as follows: Ejiao can promote hematopoiesis of bone marrow (41) and improve cellular immunity and humoral immunity in mice (42). Ejiao downregulates the expression of telomerase in lung cancer PG cell line, blocks tumor cells in the G0 stage, and induces apoptosis by suppressing Bcl-2 expression (43-45). Polysaccharide from VA activates immunocytes to kill tumor cells and deliver an anti-tumor effect in mice and immunocompromised patients (46-48).

\section{Implications for further study}

The China Food and Drug Administration promulgated the general principles of clinical research on new drugs of TCM in 2015 (49), standardizing the practice of clinical trials of TCM. Trials of this nature should henceforth be carried out with reference to this as well as the Consolidated Standards of Reporting Trials (CONSORT) statement. Random sequence generation and allocation concealment should be carefully planned and described. Double-blind trials are difficult to conduct when investigating various TCM preparations, however every effort should be made to produce an adequate placebo. The sample size should be estimated and the protocol registered online before commencement of the trial. The website link for registration should be included in the article for future checking of report bias. Detailed baseline information is required including age, pathogenesis, exact volume of uterine fibroids, and so on. The criteria should be unified for validating the effectiveness of uterine fibroids (including the improvement of fibroid symptoms and the percentage of shrink of fibroids). At present, a shrink rate of $33.3 \%$ is most commonly deemed effective (40). Symptom improvement needs to be assessed by a welldefined and standardized scale like the uterine fibroid symptom and health-related quality of life questionnaire (UFS-QOL) (50) or menstrual distress questionnaire (MDQ) (51). Serum $\mathrm{E}_{2}$ and $\mathrm{P}$ detection are generally recommended on days 3-5 of the menstrual cycle before and after the treatment. In addition, the AEs require careful observation and their incidence and treatment measures should be recorded. It is also essential that withdrawal/dropout and application of intention-to-treat analysis is clearly described.

\section{Conclusions}

The findings of 9 trials suggested that treatment containing TCM (E/VA) had more advantages over the control group in shrinking uterine fibroid and uterus volume, improving related symptoms, and reducing non-menopausal women's $\mathrm{E}_{2}$ and $\mathrm{P}$ levels., with lower incidence of AEs. Based on poor quality assessment, we cannot draw very definite conclusions, and we encourage the future conduction of well-designed trials.

\section{Acknowledgments}

Funding: This work was financially supported by the National Natural Science Foundation of China (81804163), Natural Science Foundation of Zhejiang Province (LQ15H270001), Natural Science Foundation of China (LY16H280012), Zhejiang Province Yitan Rookie Talents Project (Minchun Yang), Zhejiang Science and Technology Program of TCM (2012ZQ002).

\section{Footnote}

Reporting Checklist: The authors have completed the PRISMA reporting checklist. Available at https://dx.doi. org/10.21037/apm-21-1755

Conflicts of Interest: All authors have completed the ICMJE uniform disclosure form (available at https://dx.doi. 
org/10.21037/apm-21-1755). The authors have no conflicts of interest to declare.

Ethical Statement: The authors are accountable for all aspects of the work in ensuring that questions related to the accuracy or integrity of any part of the work are appropriately investigated and resolved.

Open Access Statement: This is an Open Access article distributed in accordance with the Creative Commons Attribution-NonCommercial-NoDerivs 4.0 International License (CC BY-NC-ND 4.0), which permits the noncommercial replication and distribution of the article with the strict proviso that no changes or edits are made and the original work is properly cited (including links to both the formal publication through the relevant DOI and the license). See: https://creativecommons.org/licenses/by-nc-nd/4.0/.

\section{References}

1. Drayer SM, Catherino WH. Prevalence, morbidity, and current medical management of uterine leiomyomas. Int $\mathrm{J}$ Gynaecol Obstet 2015;131:117-22.

2. Ciavattini A, Di Giuseppe J, Stortoni P, et al. Uterine fibroids: pathogenesis and interactions with endometrium and endomyometrial junction. Obstet Gynecol Int 2013;2013:173184.

3. Marsh EE, Al-Hendy A, Kappus D, et al. Burden, Prevalence, and Treatment of Uterine Fibroids: A Survey of U.S. Women. J Womens Health (Larchmt) 2018;27:1359-67.

4. Merrill RM. Hysterectomy surveillance in the United States, 1997 through 2005. Med Sci Monit 2008;14:CR24-31.

5. Zimmermann A, Bernuit D, Gerlinger C, et al. Prevalence, symptoms and management of uterine fibroids: an international internet-based survey of 21,746 women. BMC Womens Health 2012;12:6.

6. Rein MS, Barbieri RL, Friedman AJ. Progesterone: a critical role in the pathogenesis of uterine myomas. Am J Obstet Gynecol 1995;172:14-8.

7. Moravek MB, Bulun SE. Endocrinology of uterine fibroids: steroid hormones, stem cells, and genetic contribution. Curr Opin Obstet Gynecol 2015;27:276-83.

8. Vilos GA, Allaire C, Laberge PY, et al. The management of uterine leiomyomas. J Obstet Gynaecol Can 2015;37:157-78.

9. Yoo EH, Lee PI, Huh CY, et al. Predictors of leiomyoma recurrence after laparoscopic myomectomy. J Minim
Invasive Gynecol 2007;14:690-7.

10. Palomba S, Orio F Jr, Russo T, et al. Long-term effectiveness and safety of $\mathrm{GnRH}$ agonist plus raloxifene administration in women with uterine leiomyomas. Hum Reprod 2004;19:1308-14.

11. Qi S, Ying H Y, Wen X, et al. Effects of mifepristone on uterine leiomyoma in premenopausal women: a metaanalysis. Fertil Steril 2013;100:1722-6.e1-10.

12. Tristan M, Orozco LJ, Steed A, et al. Mifepristone for uterine fibroids. Cochrane Database Syst Rev 2012;(8):CD007687.

13. Fu Y, Fan Y, Fan W, et al. Efficacy and safety of traditional Chinese herbal formula combined with western medicine for uterine fibroid: A protocol for systematic review and meta-analysis. Medicine (Baltimore) 2020;99:e22039.

14. Tang Y, Jeon BT, Wang Y, et al. First Evidence that Sika Deer (Cervus nippon) Velvet Antler Extract Suppresses Migration of Human Prostate Cancer Cells. Korean J Food Sci Anim Resour 2015;35:507-14.

15. Wu F, Li H, Jin L, et al. Deer antler base as a traditional Chinese medicine: a review of its traditional uses, chemistry and pharmacology. J Ethnopharmacol 2013;145:403-15.

16. Xiao X, Xu S, Li L, et al. The Effect of Velvet Antler Proteins on Cardiac Microvascular Endothelial Cells Challenged with Ischemia-Hypoxia. Front Pharmacol 2017;8:601.

17. Li Y, He H, Yang L, et al. Therapeutic effect of Colla corii asini on improving anemia and hemoglobin compositions in pregnant women with thalassemia. Int J Hematol 2016;104:559-65.

18. Wang D, Ru W, Xu Y, et al. Chemical constituents and bioactivities of Colla corii asini. Drug Discov Ther 2014;8:201-7.

19. Wu H, Ren C, Yang F, et al. Extraction and identification of collagen-derived peptides with hematopoietic activity from Colla Corii Asini. J Ethnopharmacol 2016;182:129-36.

20. Wang D, Liu M, Cao J, et al. Effect of Colla corii asini (E'jiao) on D-galactose induced aging mice. Biol Pharm Bull 2012;35:2128-32.

21. Jia $M$. Treatment of 26 cases with small myoma of uterus by activating blood circulation, resolving phlegm and tonifying kidney and regulating menstruation. Zhejiang Journal of Traditional Chinese Medicine 2008;43:342.

22. Xu L, Zhang Y. Bu Shen Hua Yu San Jie method in the treat of 172 cases of hysteromyoma. Mod Tradit Chin Med 2009;29:10-1. 
23. Zhao W. Professor Zhang Liangying's experience in the treatment of uterine leiomyoma with Xiaoliu No.1. Journal of Yunnan University of Traditional Chinese Medicine 2011;34:29-30.

24. Fan P, Liang R. Clinical observation of the effect of compound E-Jiao slurry on endometrium and follicular development in 50 cases. Proceedings of the Eleventh National Academic Conference on gynecology of Chinese Medicine; 2011.

25. Ling Y, Luo F, Liu Q. Determination of sex hormones in pilose antler of traditional Chinese Medicine. Chinese Traditional and Herbal Drugs 1999;30:499-500.

26. Yang R, Zhang J, Zhou S, et al. The effect of sex hormone in milu antler on the reproductive system of rat and mouse. Acta Anatomica Sinica 2001;32:180-1.

27. Zhu M. An Investigation on the related risk factors of Endometrial Diseases and Uterine Myoma: Jilin University; 2016.

28. Mcpheeters ML, Kripalani S, Peterson NB, et al. Cochrane Risk of Bias Tool. Agency for Healthcare Research and Quality (US); 2012.

29. Yang S, Cheng Z, Zhang Z, et al. Analyzing clinical effects of gynecological Yang Rong canpsule combined with mifepristone on patients with hysteromyoma. Anti-tumor pharmacy; 2012:204-7.

30. Chen X. The therapeutic effect of Fuke Zaizao capsules combined with mifepristone on uterine fibroids. Journal of Bethune Medical Science 2017;15:257-8.

31. Zhang J. Efficacy of Fukezaizao capsules combined with mifepristone in treatment of hysteromyomab. China Medicine 2013;8:1438-9.

32. Liu W, Huang X. Effect of Fuke Zaizao capsule plus mifepristone on hysteromyoma. China Medicine 2014;9:713-5.

33. Wang S. 50 cases of uterine fibroids treated with self-made Xiaoliu capsule. Chinese Journal of Traditional Medical Science and Technology 2011;18:77.

34. Chen J, Xu F. Clinical analysis of 40 cases of menopausal syndrome complicated with uterine fibroids treated by Kuntai capsule. Chinese Remedies \& Clinics 2013;13:511-2.

35. Tao M, Shao H, Li C, et al. Correlation between the modified Kupperman Index and the Menopause Rating Scale in Chinese women. Patient Prefer Adherence 2013;7:223-9.

36. Chi J, Zhang Y. Observation on the effect of auricular pressing therapy combined with Kuntai capsule in the treatment of uterine fibroids complicated with perimenopausal syndrome. Hainan Medical Journal 2016;27:3032-5.

37. Hauser GA, Huber IC, Keller PJ, et al. Evaluation of climacteric symptoms (Menopause Rating Scale). Zentralbl Gynakol 1994;116:16-23.

38. Wang F, Pang L, Jiang L, et al. Clinical observation on Tamofen combined with Yanlurukang in the treatment of uterine fibroids with hyperplasia of mammary glands. The Practical Journal of Cancer 2015;30:840-2.

39. Liu X, Du D, Chen W. Clinical research of Fuke Zaizao Jiaonang assisted laparoscopic hysteromyomectomia in treatment of uterine fibroids. China Journal of Modern Medicine 2011;49:57.

40. Clinical guideline of new drugs for traditional Chinese medicine (the first series). Ministry of Health of the People's Republic of China; 1993.

41. Wang Z, He X, Wu B. Preliminary study on the mechanism of blood enriching effect of Ejiao. Shandong Journal of Traditional Chinese Medicine 1992:35-8.

42. Li Z, Chen BF, Huang JM, et al. Effects of gelatina Nigra on cytoimmunity and humoral immunity function in mice. Chin J Health Lab Technol 2008;18:1426-7.

43. Liu P, Tian S, You J. Research on apoptosis of compound E-Jiao Slurry human on lung cancer PG cells. Lishizhen Medicine and Materia Medica Research 2006;17:40.

44. Liu P, Cai B, You J. Research on antitumor effect of compound E-Jiao Slurry on Lewis lung cancer. Pharmacology and Clinics of Chinese Materia Medica 2005;21:44-5.

45. Liu P, Guo J, Li L. Effects of medicated serum of compound E-Jiao Slurry on Bcl-2 expression in gastric cancer cells of SGC7901 Liaoning Journal of Traditional Chinese Medicine 2008;35:185-6.

46. Kang W, Yu X, Wen J, et al. Effect of pilose antler polysaccharide on cellular immune function in immunocompromised mice. Chinese Journal of Traditional Medical Science and Technology 2000:234.

47. Tralhão JG, Schaefer L, Micegova $M$, et al. In vivo selective and distant killing of cancer cells using adenovirus-mediated decorin gene transfer. FASEB J 2003;17:464-6.

48. Xiong H. Extraction and isolation of activity component from velvet antler and research of its anti-tumor effect. Northwest A\&F University; 2007.

49. Liu B. Interpretation and drafting of general principles of clinical research on new drugs of traditional Chinese Medicine. Modernization of Traditional Chinese Medicine and Materia Medica--world science and technology 
2016;18:2075-81.

50. Harding G, Coyne KS, Thompson CL, et al. The responsiveness of the uterine fibroid symptom and healthrelated quality of life questionnaire (UFS-QOL). Health Qual Life Outcomes 2008;6:99.

Cite this article as: Li Q, Zhang L, Qian X, Ma Y, Yang W, Yang M, Ye Y. Efficacy of Chinese herbal prescriptions containing Ejiao or Velvet antler for management of uterine fibroids: a systematic review and meta-analysis of randomized controlled trials. Ann Palliat Med 2021;10(8):8772-8786. doi: 10.21037/apm-21-1755
51. Moos RH. The development of a menstrual distress questionnaire. Psychosom Med 1968;30:853-67.

(English Language Editor: J. Jones) 